\title{
Belgian consensus on metabolic problems associated with atypical antipsychotics
}

\author{
A. DE NAYER ${ }^{1}$, M. DE HERT ${ }^{2}$, A. SCHEEN ${ }^{3}$, L. VANGAAL ${ }^{4} \&$ J. PEUSKENS ${ }^{2}$ on behalf of the Consensus \\ Group*
}

${ }^{1}$ Hôpital Sainte-Thérèse, Montignie sur Sambre, Belgium, ${ }^{2}$ U.C. St-Jozef, Kortenberg, Belgium, ${ }^{3}$ Department of Medicine, CHU Sart-Tilman, Liège, Belgium, and ${ }^{4}$ Department of Diabetology, Metabolism and Nutrition, University Hospital of Antwerp, Edegem (Antwerp), Belgium

\begin{abstract}
A workshop was convened by a panel of psychiatrists, diabetologists and pharmacists from major Belgian hospitals to review the latest information relating to the risks with second-generation antipsychotics (SGA) for the development of metabolic disorders, especially impaired glucose tolerance, diabetes mellitus and dyslipidemia. The panelists sought to formulate recommendations for practising psychiatrists when initiating and maintaining therapy with SGA, and for the switch of SGA or initiation of further treatment if metabolic complications occur. In addition, recommendations for counselling of the patient and for the cooperation between the psychiatrist and the general physician or diabetologist, respectively, were provided.
\end{abstract}

Key Words: Consensus, diabetes, metabolic, dyslipidemia, second-generation antipsychotics

\section{INTRODUCTION}

\section{Objectives of the workshop}

On 31 March, 10 May, and 5 July 2004 a three-part workshop was held in the University Centre of St.-Jozef in Belgium with the purpose to discuss important metabolic issues faced by patients on antipsychotic drugs. The meeting was scheduled against the background of a series of reports and mostly retrospective studies, suggesting a substantially increased risk for impaired glucose regulation, weight gain, manifest diabetes mellitus, and dyslipidemia at least for some of the second-generation antipsychotics (SGA). These risk factors and markers are closely associated with increased cardiovascular risk. However, there are still many unanswered questions concerning this issue and more research has been recommended recently by both the American Psychiatric Association in cooperation with the American Diabetes Association [1], as well by a British working group that published the consensus in the British Journal of Psychiatry [2].

The recently published consensuses for the management of metabolic complications associated with SGA might be insufficiently sensitive: in light of our data [3], it seems that screening with fasting glucose misses a number of patients with impaired glucose metabolism and, taking into account the possibility of possible reversal of the metabolic complication with early withdrawal of the incriminated medication, metabolic screening should be more frequent during the first 6 months; also the importance of the hyperlipidemia demands more frequent monitoring.

A group of 17 invited participants, including psychiatrists, pharmacists, endocrinologists/diabetologists, and general physicians discussed the current state of knowledge (for full details, see appendix). On the basis of the available information, the expert panel aimed to formulate pragmatic consensus recommendations for the practising psychiatrists.

\footnotetext{
* For members and affiliations see Appendix.
} 


\section{Structure of the report}

The report is divided into two sections. The first section provides a brief overview of the topics that were presented and considered by the participants at the meeting. The second section summarizes the consensus reached and the recommendations arising.

\section{BACKGROUND}

\section{First- and second-generation antipsychotics}

Schizophrenia certainly is a severe and devastating mental illness, and is characterised by a chronic and recurrent natural course. This disease which has a lifetime prevalence of approximately $1 \%$ worldwide is associated with high morbidity and mortality. Antipsychotic medications are the mainstay of treatment for psychotic illnesses. Following the introduction of the first-generation antipsychotics about half a century ago, these drugs have helped millions of people manage their symptoms. For people who respond well, antipsychotics mean the difference between leading an engaged, fulfilling community life and being severely disabled [1].

The introduction of SGA has profoundly changed the treatment of schizophrenia. SGA are as or even more effective and have - in general - more favourable safety profiles than those achieved with the conventional antipsychotics. A substantial gain has been obtained for extrapyramidal symptoms and dyskinesia, whose incidence is much lower with SGA.

As a consequence, with the exception of clozapine, they have become the first line agents for their indicated use. Besides that, they are increasingly used in other indications such as bipolar disorder, dementia, psychotic depression, personality disorders and posttraumatic stress disorder [1]. In view of the high prevalence of these disorders, SGA are widely used medications, and their use has important public health implications.

\section{Diabetes mellitus: definitions}

Diabetes mellitus is a prevalent multisystem metabolic disease which is characterised by elevated blood glucose levels and by micro- and macrovascular complications that substantially increase the morbidity and mortality associated with the disease and reduce the quality of life [4]. Microvascular complications comprise retinopathy and nephropathy, while macrovascular complications include coronary heart disease, stroke and peripheral arterial disease. Peripheral neuropathy is frequently associated with the diabetic foot.

The major types of diabetes are type 1 and type 2 diabetes [5]. Type1 diabetes is caused by the autoimmune destruction of the pancreatic $\beta$ cells and characterized by total reliance on exogenous insulin for survival. While type 1 diabetes usually occurs in adolescent patients, recent research suggests that autoimmune forms of diabetes might be the underlying cause for up to $10-15 \%$ of cases in adults and the elderly, respectively (type 1.5 diabetes [6], latent diabetes in adults [7]).Type 2 diabetes, accounting for $90 \%$ of all cases, results from impaired insulin secretion from the $\beta$ cells and resistance to the action of insulin.

The natural history of diabetes includes an asymptomatic preclinical phase, which is characterised by impaired glucose regulation. The terms "impaired glucose tolerance" (IGT) and "impaired fasting glucose" (IFG) represent metabolic states intermediate between normal glucose homeostasis and diabetic hyperglycemia [8]. Both IGT and IFG are considered as risk categories for the future development of diabetes and cardiovascular diseases and premature death. For example, up to half of all people with IGT will progress to type 2 diabetes within 10 years of diagnosis. IGT and IFG are components of the metabolic syndrome, thereby heightening the patient's risk [8]. Table Ia displays the diagnostic criteria for diagnosis of IGT, IFG, and diabetes.

\section{Association of schizophrenia and antipsychotics with metabolic disorders}

The current literature supports that schizophrenia (and other psychiatric disorders such as bipolar disorders) appear to be associated with a higher prevalence of type 2 diabetes. Because of the silent nature of diabetes mellitus, and the fact that schizophrenic patients are not screened comprehensively for the disease, the true prevalence of hyperglycemia and diabetes may be substantially underestimated $[9,10]$. Notably, it has been suggested that schizophrenia as such carries an increased risk, as certain characteristics of schizophrenic patients such as unhealthy life style (e.g., true and perceived stress, eating habits, overweight, and sedentary lifestyle) promote the risk of diabetes. 
This risk may be increased by antipsychotic drug treatment, as was already suggested for first-generation antipsychotics (FGA) [11]. The amount of literature on the association of SGA and metabolic disorders is much larger than for FGA; however, well-controlled prospective data are sparse. Reports comprise abnormal glucose regulation, exacerbation of existing type 1 and type 2 diabetes, new-onset pseudo-type 1 or type 2 diabetes, diabetic ketoacidosis, coma and death. In a number of large-scale studies (mostly retrospective by nature), reviews and meta-analyses, the association was not found for all drugs [12-18].

According to recent reviews, the risk of developing diabetes was highest for clozapine and olanzapine, followed by, quetiapine and risperidone [1,19-23]. The hierarchy of liability of weight gain due to antipsychotics was in the same described order.

Table Ia. Values for diagnosis of diabetes mellitus and other categories of hyperglycaemia according to WHO.

\begin{tabular}{|c|c|c|c|}
\hline & & entration, $\mathrm{mmol} \mathrm{l}^{-1}$ & $\left.\mathrm{dl}^{-1}\right)$ \\
\hline & & od & Plasma* \\
\hline & Venous & Capillary & Venous \\
\hline Diabetes Mellitus: & & & \\
\hline Fasting or & $\geq 6.1(\geq 110)$ & $\geq 6.1(\geq 110)$ & $\geq 7.0(\geq 126)$ \\
\hline 2-h post glucose load or both & $\geq 10.0(\geq 180)$ & $\geq 11.1(\geq 200)$ & $\geq 11.1(\geq 200)$ \\
\hline Impaired Glucose Tolerance (IC & $:$ & & \\
\hline Fasting (if measured) and & $<6.1(<110)$ & $<6.1(<110)$ & $<7.0(<126)$ \\
\hline 2-h post glucose load & $\geq 6.7(\geq 120)$ and & $\geq 7.8(\geq 140)$ and & $\geq 7.8(\geq 140)$ and \\
\hline & $<10.0(<180)$ & $<11.1(<200)$ & $<11.1(<200)$ \\
\hline Impaired Fasting Glycaemia (IF & & & \\
\hline Fasting and (if measured) & $\geq 5.6(\geq 100)$ and & $\geq 5.6(\geq 100)$ and & $\geq 6.1(\geq 110)$ and \\
\hline & $<6.1(<110)$ & $<6.1(<110)$ & $<7.0(<126)$ \\
\hline 2-h post glucose load & $<6.7(<120)$ & $<7.8(<140)$ & $<7.8(<140)$ \\
\hline ource: World Health Organisation 19 & & & \\
\hline * Corresponding values for capillary pla & re: for Diabetes Mellitus, & 26), $2-\mathrm{h} \geq 12.2(\geq 220)$ & ired Glucose \\
\hline Tolerance, fasting $<7.0(<126)$ and $2-h$ & $>160)$ and $<12.2(<220$ & ed Fasting Glycaemia & $0)$ and $<7.0(<126)$ \\
\hline and if measured, $2-\mathrm{h}<8.9(<160)$. & & & 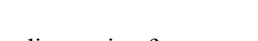 \\
\hline $\begin{array}{l}\text { *If fasting blood glucose is } \geq 126 \mathrm{mg} / \mathrm{dl} \text {, } \\
\text { diabetes is met. }\end{array}$ & irmed by a repeat testing & lifferent day, the threst & diagnosis of \\
\hline Notes: IGT and IFG are not mutually ex & re, and may occur in the s & & \\
\hline $\begin{array}{l}\text { The American Diabetes Association ha } \\
\text { [45]. }\end{array}$ & tly established a cutpoin & ahpye which nersons & IFG or diabetes \\
\hline
\end{tabular}

Indeed, and in accordance with the observation of weight gain being a risk factor for glucose metabolism disorders in the general population, weight gain was identified in a study performed on the WHO database as a risk factor for antipsychotic-induced glucose intolerance [24]. However, only 5.6\% of patients with glucose intolerance experienced weight gain. Therefore, while some of this effect is mediated through increased adiposity, there is evidence for an independent effect of these agents on insulin resistance/production and on lipidemia.

In order to give an indication about the size of the problem, Koller et al., in an extensive pharmacovigilance survey, queried the Food and Drug Administration (FDA) MedWatch system for cases of hyperglycemia and diabetes mellitus associated with clozapine [25], olanzapine [26], risperidone [27] and quetiapine [28], and pooled the results with published cases. The results on olanzapine serve as an example: 237 olanzapineassociated cases of diabetes or hyperglycemia were reported between 1994 and 2001. Of these, 188 were newonset diabetes, 44 were exacerbations of preexistent disease, and five could not be classified. Incidental diabetes occurred between 2 days and 45 months after treatment initiation (for $73 \%$ less than 6 months), while no correlation was found between dose and glucose level or dose and time to onset. Eighty patients had metabolic acidosis or ketosis, 41 had glucose levels of $\geq 1000 \mathrm{mg} / \mathrm{dl}$, and 15 patients died. When olanzapine was discontinued or the dosage decreased, 78\% had improved glycemic control [26].

Underlying mechanisms may include the following: direct genetic effect, decreased insulin sensitivity independent of SGA medication, increased insulin resistance related to SGA, decreased insulin production, effects of SGA on 5-HT2c receptors [19]. 
Apart from disturbances in glucose metabolism, further frequent metabolic abnormalities in schizophrenic patients on SGA include features of the metabolic syndrome [29, 30]. Diagnostic criteria are summarized in Table Ib. Dyslipidemia is a feature of type 2 diabetes, and antipsychotics such as clozapine and olanzapine have also been associated with hypertriglyceridemia [29], while agents such as haloperidol, risperidone, and ziprasidone were associated with reductions in plasma triglycerides [31].

Amisulpride, aripiprazole, and ziprasidone seem to carry the lowest risk for weight gain and effects on insulin resistance.

As a consequence, there is a shift in attention toward physical health monitoring in patients with mental health disorders [32-35]. The American Psychiatric Association and American Diabetes Association have recently published the findings on SGA and metabolic abnormalities in a joint statement (Table Ic) [29].

\section{Situation in Belgium, according to a prospective study}

In the U.C. St-Jozef, currently a large prospective study (at this moment, including 250 patients) until today on metabolic disturbances in non-diabetic schizophrenic patients is ongoing. An oral glucose tolerance test (OGTT) was performed in all patients. The aim is to follow patients included in the study prospectively for 1 year, and to retest them at regular intervals (including a repeat OGTT).

Table Ib. ATP III Clinical identification of the metabolic syndrome.

\begin{tabular}{ll}
\hline Risk Factor & Defining Level \\
\hline Abdominal obesity, given as waist circumference* $\dagger$ \\
Men & $>102 \mathrm{~cm}$ \\
Women & $>88 \mathrm{~cm}$ \\
Triglycerides & $\geq 150 \mathrm{mg} / \mathrm{dl}$ \\
HDL cholesterol & \\
Men & $<40 \mathrm{mg} / \mathrm{dl}$ \\
Women & $<50 \mathrm{mg} / \mathrm{dl}$ \\
Blood pressure & $\geq 130 / \geq 85 \mathrm{~mm} \mathrm{Hg}$ \\
Fasting glucose & $\geq 110 \mathrm{mg} / \mathrm{dl} * *$ \\
\hline
\end{tabular}

Source: National Panel on Detection, Evaluation and Treatment of High Blood Cholesterol in Adults (NCEP) Adult Treatment Program III [36].

*Overweight and obesity are associated with insulin resistance and the metabolic syndrome. However, the presence of abdominal obesity is more highly correlated with the metabolic risk factors than is an elevated BMI. Therefore, the simple measure of waist circumference is recommended to identify the body weight component of the metabolic syndrome.

$\uparrow$ Some patients can develop multiple metabolic risk factors when the waist circumference is only marginally increased, e.g., in men $94-102$ $\mathrm{cm}$, in women $80-88 \mathrm{~cm}$. Such patients may have a strong genetic contribution to insulin resistance. They should benefit from changes in life habits, similarly to men with categorical increases in waist circumference.

**The American Diabetes Association has recently established a cutpoint of $\geq 100 \mathrm{mg} / \mathrm{dl}$, above which persons have either IFG or diabetes [45]. This new cutpoint should be applicable for identifying the lower boundary to define an elevated glucose as one criterion for the metabolic syndrome.

A preliminary cross-sectional analysis on 100 schizophrenic patients (mean age 38 years and stable on medication for more than 6 months), showed glucose abnormalities in 22\% of patients [3]: 4\% met criteria of diabetes (of whom two patients had glucose values above $200 \mathrm{mg} / \mathrm{dl}$ at $120 \mathrm{~min}$ after glucose load, both with IFG), $16 \%$ met criteria of IGT and $2 \%$ had IFG without other glucose abnormalities. Of these relatively young patients, 22\% met ATP-III criteria for the metabolic syndrome, as published by the Expert Panel on Detection, Evaluation and Treatment of Blood Cholesterol in adults (for criteria see Table II) [36]. Fourteen of the 16 patients with IGT had normal fasting glucose levels while, as a group, patients with IGT had significantly higher fasting insulin levels compared to patients with normal glucose tolerance $(P=0.0003)$.

A monitoring protocol based only on fasting glucose would have accounted for only $12.5 \%$ of IGT and half of diabetes cases. Overall, $63.6 \%$ of patients with classifiable glucose abnormalities would not have been detected [37]. 
Table Ic. SGA and metabolic abnormalities.

\begin{tabular}{lccc}
\hline Drug & Weight gain & Risk for diabetes & Worsening lipid profile \\
\hline Clozapine & +++ & + & + \\
Olanzapine & +++ & + & + \\
Risperidone & ++ & $?$ & $?$ \\
Quetiapine & \pm & $?$ & $?$ \\
Ziprasidone & \pm & No report & No report \\
Amisulpride* & \pm & No report & No report \\
\hline
\end{tabular}

Source: American Psychiatric Association (APA) and American Diabetes Association (ADA) 2004 [1].

According to existing evidence: $+=$ increase effect, $-=$ no effect, $?=$ discrepant results.

Aripiprazole was omitted, as not marketed in Belgium.

*Amisulpride was added to the table, risk assessment is according to consensus of the Belgian group.

\section{Regulatory situation}

The various regulatory authorities have translated the current evidence differently in the labelling text. Although aripiprazole and ziprasidone had no case report of hyperglycemia, the FDA has imposed a uniform labelling to all SGA on the US market (clozapine, olanzapine, quetiapine, ziprasidone, aripiprazole, risperidone):

"Hyperglycemia, in some cases extreme and associated with ketoacidosis or hyperosmolar coma or death has been reported in patients treated with atypical antipsychotics" [38]. As for Europe, the olanzapine and risperidone labels approved by the Committee for Proprietary Medicinal Products (CPMP) - and the Belgian health authorities - mention the hyperglycemia and diabetes risk. No mention of these conditions is made with amisulpride and quetiapine.

\section{CONSENSUS STATEMENTS AND RECOMMENDATIONS}

\section{How should the basic metabolic risk be managed?}

Untreated patients with schizophrenia in comparison to healthy individuals have an increased basic risk to develop metabolic disorders. Notably, they are to a certain extent predisposed to develop diabetes mellitus. Therefore, a comprehensive approach should be taken.

The initial visit before prescribing a SGA to a patient is of particular importance, and patients having risk factors for metabolic complications should be identified early. Their family and metabolic history should be elucidated by the psychiatrist in detail. Using the categories in Table III might prove helpful for the treating physician for identifying susceptible patients.

Table II. ATP III Classification of LDL, total and HDL cholesterol (mg/dl).

\begin{tabular}{ll}
\hline LDL & \\
$<100$ & Optimal \\
$100-129$ & Near or above optimal \\
$130-159$ & Borderline high \\
$160-189$ & High \\
$\geq 190$ & Very high \\
Total cholesterol & \\
$<200$ & Desirable \\
$200-239$ & Borderline high \\
$\geq 240$ & High \\
HDL & \\
$<40$ & Low \\
$\geq 60$ & High
\end{tabular}

LDL, density lipoprotein; HDL, high density lipoprotein. Source: National Panel on Detection, Evaluation and Treatment of High Blood Cholesterol in Adults (NCEP) Adult Treatment Program III [36]. 
The psychiatrist should also initiate the laboratory screening. Measuring the fasting blood glucose is the minimum (for diagnostic criteria, refer to Table Ia). To increase sensitivity of screening, fasting insulin can be measured and insulin sensitivity in the homeostatic model (HOMA-IR) calculated [39]. Calculation of insulin resistance (HOMA-IR) from fasting glucose and fasting insulin has been suggested to be of value for prediction of diabetes in the above-mentioned Belgian prospective study [3]. However, insulin levels are not standardised and insulin measurements are not part of the standard screening protocol.

The OGTT is the gold standard screening test in high risk populations (identified by medical history), but under daily practice conditions, the fasting plasma glucose test is more convenient [40]. However, it lacks sensitivity and may miss a number of patients with diabetes [3]. The HbAlc (glycosylated haemoglobin) is an acknowledged measure of average glycemic control for the preceding 6-8 weeks, but is not suitable to screen patients for diabetes.

While looking for risk factors for developing diabetes in the patient, it is important to note that predictors for the most severe cases (ketoacidosis) -which are unusual - are not known.

In choosing between SGA with equal efficacy, an SGA considered to have a low propensity for weight gain and diabetes is to be preferred (such as amisulpride, aripiprazole, or ziprasidone, see Table Ic). If SGA with a high risk for metabolic effects are indicated, the follow-up should be close, and the treating general practitioner (GP)/internist should be informed.

Smoking cessation should be advised in all patients because of the convincing documentation of the causal link between smoking and health risk. In addition, it is known that smoking impairs glucose transport. As substantial weight gain can occur after stopping smoking, smoking cessation counselling should be a routine component of care. For details of the recommendations for the visit before starting SGA see Table IV.

Table III. Risk factors/profile for development of cardiovascular and metabolic disorders.

\begin{tabular}{ll}
\hline Medical factors & $\begin{array}{l}\text { obesity, dyslipidemia, hypertension, smoking, hyperglycemia, } \\
\text { diabetes }\end{array}$ \\
Behavioural factors & poor diet, smoking, physical inactivity, high stress \\
Genetic factors & ethnicity, family history or metabolic or cardiovascular disease \\
\hline Adapted from Casey et al. [22].
\end{tabular}

\section{How should patients on SGA be followed up?}

Patients should be counselled about measuring and charting their own weight and waist circumference. Patients on SGA should undergo regular laboratory blood testing of blood sugar, blood lipids, as well as body weight and blood pressure. Table $\mathrm{V}$ displays the recommended time intervals between measurements of these parameters.

\section{How to proceed when the patient develops SGA associated IFG or diabetes?}

If IFG ( $\geq 100 \mathrm{mg} / \mathrm{dl}$ ) is detected, confirmed by a retest on another day, risk factors should be evaluated, and the frequency of follow-up examinations increased. A GP or specialist should be consulted. The calculation of HOMA-IR as well as an OGTT should be considered. Depending on the results, it should be considered to switch the patient to an SGA that has not been associated with significant weight gain or diabetes (see Table Ic). In addition to lifestyle changes and diet, in patients with IFG the administration of metformin to prevent progression to overt diabetes may be considered.

If fasting blood glucose $\geq 126 \mathrm{mg} / \mathrm{dl}$ is confirmed on another day (i.e., diabetes diagnosis), the patient should be switched to a SGA that has not been associated with significant weight gain or diabetes (see Table Ic). If a switch of medication is not possible (e.g., patients on clozapine), diabetes has to be treated with non-drug (lifestyle modification, diet) or drug treatment (oral antidiabetic drugs or insulin). The consultation of a GP or internist/ endocrinologist is recommended.

If the diagnosis of diabetes is made, it may in some cases be reversible if drugs are withdrawn early. 
Table IV. Components of the visit before prescription of SGA.

Medical history, focussing on metabolic problems and on family history

- Symptoms, results of laboratory tests, and special

examinations, if any, related to the diagnosis of diabetes

- Prior fasting blood glucose, OGTT, or HbAlc records

- Family history of diabetes or overweight/obesity

- Eating patterns, nutritional status, weight history

- Exercise history

- Other medications or drugs affecting blood glucose levels (valproate, lithium, etc.)

- Risk factors for atherosclerosis: smoking, hypertension, obesity, dyslipidemia, and family

history

- Prior nutrition education, attitudes, and health beliefs

- Tobacco, alcohol abuse and/or controlled substance use Physical examination

- Measurement of height and weight, calculation of Body Mass Index

- Waist circumference*

- In-depth physical examination

- Blood pressure

Laboratory examination

- Fasting plasma glucose

- Fasting lipid profile (total cholesterol, LDL cholesterol, HDL cholesterol, triglycerides)

Counselling

- on the diabetic risk associated with the underlying disease and with SGA

- on signs of ketoacidosis and other diabetic complications

- on life styles issues (smoking cessation, nutrition, self-monitoring of weight)

*To be measured in the middle between iliac crest and lower rib cartilage.

OGTT, oral glucose tolerance test.

Table V. Recommended schedule of monitoring for patients taking SGA.

\begin{tabular}{|c|c|}
\hline $\begin{array}{l}\text { Weight and waist } \\
\text { circumference }\end{array}$ & Weekly in hospital care, monthly in ambulatory care \\
\hline \multirow[t]{3}{*}{ Fasting blood glucose* } & Depending on risk factors and drugs ${ }^{* *}$. \\
\hline & $\begin{array}{l}\text { Monthly in patients with family history of diabetes/obesity and/or with manifest } \\
\text { overweight or obesity, and/or with impaired fasting glucose, }\end{array}$ \\
\hline & After 6 and 12 weeks, then quarterly in patients without risk factors \\
\hline \multirow[t]{2}{*}{ Fasting blood lipids } & Total cholesterol, HDL cholesterol, LDL cholesterol, triglycerides \\
\hline & Every 3 months for the first year of treatment, then annually \\
\hline Blood pressure & Every 3 months \\
\hline
\end{tabular}

\section{Management of SGA-induced dyslipidemia}

In patients who develop dyslipidemia while on SGA therapy (for reference values, see ATP III recommendations in Table Ib and II), after a confirmatory lab test, a diet should be tried. If no satisfactory effect is achieved, a switch to SGA with a lower risk of metabolic side effects is recommended (see Ic). If a medication change is contraindicated, a GP or specialist should be consulted, who will initiate further treatment steps (e.g., lipidlowering medication).

\section{Management of SGA-induced obesity}

Weight gain should be prevented by choosing a safe SGA in overweight patients. Patients should be counselled on lifestyle changes and dietary measures at the initiation of and during antipsychotic therapy. Concerning diet and exercise, patients should (a) decrease the fat and energy content of their diet and increase fibre intake, (b) eat more fruits and vegetables, (c) eat complex rather than simple carbohydrates, (d) avoid sugary drinks, and (e) exercise for at least 10-15 min per day [41], ideally 30 min per day [42]. In patients with significant weight gain 
( $\geq 7 \%$ ), a change of medication to a drug that is associated with a lesser weight gain should be considered. If no satisfactory treatment effect is achievable, a GP's or internist's and/or dietetician's advice should be sought. In terms of drug-treatment for being overweight, orlistat is expensive and problems in absorption of antipsychotics may occur; sibutramine has been suspected to induce psychotic symptoms and is contraindicated for individuals with psychiatric disorders.

\section{Which recommendations can be given for patients with other mental disorders treated with SGA?}

SGA are used in a broad spectrum of indications, including bipolar disorder, psychotic depression, dementia, autism, developmental delay, and others [1,14]. Data on the relationship between mental disorders other than schizophrenia and metabolic disorders are limited. However, certain patient groups, e.g., those with mood disorders, also appear to be at increased risk [14, 43, 44]. Accordingly, a cautious attitude is recommended: these patients should also be screened and monitored as described above. Patients with medications known to increase the risk of weight gain, such as mood stabilizers, should be closely followed-up. Patients and their families or caregivers should be counselled about the possible metabolic complications. If those occur, change of medication to drugs with a lower metabolic risk should be considered.

\section{How should the patient be informed about the metabolic effects of SGA?}

When starting treatment with SGA, the need of antipsychotic maintenance therapy, the risks of not taking any medications, and the advantages of SGAs should be discussed with the patient. By the same token, the patient should be counselled on the metabolic risk of the underlying disease and the risks associated the planned drug SGA treatment. Patient information includes the risk of diabetes and IFG, weight gain, and dyslipidemia, and measures to prevent these conditions (lifestyle changes, diet).

Since diabetic ketoacidosis cannot be foreseen, patient education on this condition is mandatory. Specifically, the patient, family members and caregivers must be educated about the warning signs of the acute decompensation of diabetes, as it is life-threatening, albeit infrequent. Diabetic ketoacidosis includes the rapid onset of polyuria and polydipsia, weight loss, nausea and vomiting, dehydration, rapid respiration, and sensory clouding, leading to coma.

\section{Recommendations for the collaboration between the psychiatrist with the GP or the diabetologist}

According to the present recommendations, the psychiatrist initiates the screening and follow-up measures. If tests, however, indicate impaired glucose metabolism, diabetes, dyslipidemia, or hypertension, the future management of these physical diseases should be primarily provided by a GP or internist/diabetologist. Close communication should be maintained by the psychiatrist and GP, especially concerning change or maintenance of medications.

The primary goal of therapy is to achieve best control of the mental disease of the patient. Nonetheless, metabolic control should be aimed at as well.

\section{Key points}

- SGA with the lowest risk profile (amisulpride, aripiprazole, ziprasidone) are to be preferred

- Patients having risk factors for metabolic complications should be identified early, before SGA initiation

- Frequency of the monitoring should be adapted to the metabolic status (risk factors; pre-existing obesity, hyperlipidaemia or glucose metabolism disorders) of the patient and to the metabolic risk profile associated to the chosen SGA

- Treatment-emergent metabolic disorders warrant switch of the SGA to a lower risk profile-associated agent and management of the complication in collaboration with the GP/endocrinologist

- Patients should be informed about the management of their mental illness and the metabolic risk associated to SGA

\section{Statement of interest}

The author has no conflict of interest with any commercial or other associations in connection with the submitted article. 
Published in: International Journal of Psychiatry in Clinical Practice (2005) vol.9, iss.2, pp.130-137

Status: Postprint (Author's version)

\section{References}

[1] Consensus Development Conference on Antipsychotic Drugs and Obesity and Diabetes. Diabetes Care 2004;27:596-601.

[2] 'Schizophrenia and Diabetes 2003' Expert Consensus Meeting, Dublin, 3-4 October 2003: consensus summary. Br J Psychiatry 2004; 184:S112-4.

[3] De Hert M, Van Eyck D, Peuskens H, Thys E, Peuskens J. Prevalence of impaired glucose tolerance in schizophrenic patients [abstract]. Annual Meeting of the American Psychiatric Society, 2004.

[4] Diagnosis and Classification of Diabetes Mellitus. Diabetes Care 2004; 27:S5-10.

[5] World Health Organization. Definition, diagnosis and classification of diabetes mellitus and its complications. Report of a WHO Consultation. Part 1: Diagnosis and classification of diabetes mellitus. Geneva, 1999.

[6] Palmer JP, Hirsch IB. What's in a name: Latent autoimmune diabetes of adults, type 1.5, adult-onset, and type 1 diabetes. Diabetes Care $2003 ; 26: 536-8$.

[7] Tuomi T, Groop L, Zimmet P, Rowley M, Knowles W, Mackay I. Antibodies to glutamic acid decarboxylase reveal latent autoimmune diabetes mellitus in adults with a non-insulin-dependent onset of disease. Diabetes 1993;42:359-62.

[8] Unwin N, Shaw J, Zimmet P, Alberti KG. Impaired glucose tolerance and impaired fasting glycaemia: the current status on definition and intervention. Diabet Med 2002; 19:708-23.

[9] Mukherjee S, Decina P, Bocola V, Saraceni F, Scapicchio PL.Diabetes mellitus in schizophrenic patients. Compr Psychiatry 1996; 37:68-73.

[10] Subramaniam M, Chong SA, Pek E. Diabetes mellitus and impaired glucose tolerance in patients with schizophrenia. Can J Psychiatry $2003 ; 48: 345-7$.

[11] Dynes JB. Diabetes in schizophrenia and diabetes in non-psychotic medical patients. Dis Nerv Syst 1969; 30:341-4.

[12] Citrome LL, Jaffe AB. Relationship of atypical antipsychotics with development of diabetes mellitus. Ann Pharmac-other 2003; $37: 1849-57$.

[13] Henderson DC. Atypical antipsychotic-induced diabetes mellitus: how strong is the evidence? CNS Drugs 2002; 16:77-89.

[14] Gianfrancesco FD, Grogg AL, Mahmoud RA, Wang RH, Nasrallah HA. Differential effects of risperidone, olanzapine, clozapine, and conventional antipsychotics on type 2 diabetes: findings from a large health plan database. J Clin Psychiatry 2002; 63:920-30.

[15] Clark C, Burge MR. Diabetes mellitus associated with atypical anti-psychotic medications. Diabetes Technol Ther 2003; 5:669-83.

[16] Koro CE, Fedder DO, L'Italien GJ, et al. Assessment of independent effect of olanzapine and risperidone on risk of diabetes among patients with schizophrenia: population based nested case-control study. Br Med J 2002; 325:243.

[17] Sernyak MJ, Leslie DL, Alarcon RD, Losonczy MF, Rosenheck R. Association of diabetes mellitus with use of atypical neuroleptics in the treatment of schizophrenia. Am J Psychiatry 2002; 159:561-6.

[18] Caro JJ, Ward A, Levinton C, Robinson K. The risk of diabetes during olanzapine use compared with risperidone use: a retrospective database analysis. J Clin Psychiatry 2002; 63:1135-9.

[19] Melkersson K, Dahl ML. Adverse metabolic effects associated with atypical antipsychotics: literature review and clinical implications. Drugs 2004;64:701-23.

[20] Meyer JM, Koro CE. The effects of antipsychotic therapy on serum lipids: a comprehensive review. Schizophr Res 2004; 70:1-17.

[21] Jin H, Meyer JM, Jeste DV. Atypical antipsychotics and glucose dysregulation: a systematic review. Schizophr Res 2004; 71:195-212.

[22] Casey DE, Haupt DW, Newcomer JW, et al. Antipsychotic-induced weight gain and metabolic abnormalities: implications for increased mortality in patient with schizophrenia. J Clin Psychiatry 2004; 65:4-18.

[23] Scheen A, De Hert M. Risque de diabete sucre sous antipsychotiques atyptiques. Méd Hyg 2004:1591-6.

[24] Hedenmalm K, Hagg S, Stahl M, Mortimer O, Spigset O. Glucose intolerance with atypical antipsychotics. Drug Saf 2002;25:1107-16.

[25] Koller E, Schneider B, Bennett R, Dubitsky G. Clozapine-associated diabetes. Am J Med 2001; 111:716-23. 
Published in: International Journal of Psychiatry in Clinical Practice (2005) vol.9, iss.2, pp.130-137

Status: Postprint (Author's version)

[26] Koller EA, Doraiswamy PM. Olanzapine-associated diabetes mellitus. Pharmacotherapy 2002;22:841-52.

[27] Koller EA, Cross JT, Doraiswamy PM, Schneider BS. Risperidone-associated diabetes mellitus: a pharmacovigi-lance study. Pharmacotherapy 2003; 23:735-44.

[28] Roller EA, Weber J, Doraiswamy PM, Schneider BS. A survey of reports of quetiapine-associated hyperglycemia and diabetes mellitus. J Clin Psychiatry 2004; 65:857-63.

[29] Consensus development conference on antipsychotic drugs and obesity and diabetes. J Clin Psychiatry 2004; 65:267-72.

[30] Grundy SM, Brewer HB Jr, Cleeman JI, Smith SC Jr, Lenfant C, for the Conference Participants. Definition of Metabolic Syndrome: Report of the National Heart, Lung, and Blood Institute/American Heart Association Conference on Scientific Issues Related to Definition. Circulation 2004; 109:433-8.

[31] Haupt DW, Newcomer JW. Hyperglycemia and antipsychotic medications. J Clin Psychiatry 2001;62(Suppl 27):15-26; discussion 40-1.

[32] Henderson D. Medical Illness and Schizophrenia. In: Meyer J, Nasrallah H, editors. Washington, DC: Am Psy Publishing, 2003.

[33] Marder SR, Essock SM, Miller AL, et al. Physical health monitoring of patients with schizophrenia. Am J Psychiatry 2004; 161:133449.

[34] Roro CE, Bowlin SJ, Bourgeois N, Fedder DO. Glycemic control from 1988 to 2000 among U.S. adults diagnosed with type 2 diabetes: a preliminary report. Diabetes Care 2004;27:17-20.

[35] Nasrallah H, Rorn M. Metabolic Disorders in Schizophrenia: Relationship to Atypical Antipsychotic Treatment, posted 07/28/2004: Medscape Psychiatry and Mental Health schizophrenia expert column, 2004.

[36] Executive Summary of The Third Report of The National Cholesterol Education Program (NCEP) Expert Panel on Detection, Evaluation, And Treatment of High Blood Cholesterol In Adults (Adult Treatment Panel III). J Am Med Assoc 2001;285:2486-97.

[37] Cohn T, Wolever T, Zipursky R, et al. Screening for diabetes and impaired glucose tolerance in patients on antipsychotic medication. J Neuropsychopharmacol 2002;5(Suppl I):168.

[38] Rosack J. FDA to require diabetes warning on antipsychotics. Psychiatr News 2003;38:1-a-27.

[39] Haffner SM, Miettinen H, Stern MP. The homeostasis model in the San Antonio Heart Study. Diabetes Care 1997;20:1087-92.

[40] American Diabetes Association. Standards of medical care for patients with diabetes mellitus. Diabetes Care 2002;26(Suppl 1):33-50.

[41] Gough S, Pelever R. Diabetes and its prevention: pragmatic solutions for people with schizophrenia. Br J Psychiatr 2004;184:S106-11.

[42] Rnowler WC, Barrett-Connor E, Fowler SE, et al. Reduction in the incidence of type 2 diabetes with lifestyle intervention or metformin. New Engl J Med 2002;346:393-403.

[43] Regenold WT, Thapar RR, Marano C, Gavirneni S, Rondapavuluru PV. Increased prevalence of type 2 diabetes mellitus among psychiatric inpatients with bipolar I affective and schizoaffective disorders independent of psychotropic drug use. J Affect Disord 2002; $70: 19-26$

[44] Gianfrancesco F, Grogg A, Mahmoud R, Wang RH, Meletiche D. Differential effects of antipsychotic agents on the risk of development of type 2 diabetes mellitus in patients with mood disorders. Clin Ther 2003;25:1150-71.

[45] Genuth S, Alberti RG, Bennett P, et al. Follow-up report on the diagnosis of diabetes mellitus. Diabetes Care 2003;26:3160-7.

\section{Appendix A: Workshop members}

\section{Co-Chairpersons}

J. Peuskens, A. De Nayer

\section{Participants}

C. Bervoets (PZ Onze Lieve Vrouw, Brugge); M. De Hert (U.C. St-Jozef, Kortenberg); A. De Nayer (CH SteThérèse, Gilly); J.-M. Devoitille (CH Psychiatrique de Liège - Le Petit Bourgogne); J.-M. Domken (CHP du "Chêne aux haies", Mons); J. Hulselmans (P.Z. Stuivenberg, Antwer-pen); D. Lecompte (CHU-Brugman, Bruxelles); F. Lotstra (CHU Erasme, Bruxelles); F. Mathot (CH Psychiatrique de Liège - Le Petit Bourgogne); C. Mertens (P.Z. St-Camillus, Gent); J. Peuskens (U.C. St-Jozef, Kortenberg); J. Reyntens (Clinical Pharmacist 
Psychiatrisch Centrum Sint-Jan Eeklo); A. Scheen (Division of Diabetes, Nutrition and Metabolic Disorders, Department of Medicine, CHU Sart Tilman, Liège); A. Seghers (CHU St-Luc, Bruxelles); E. Stillemans (CH Jean Titeca, Bruxelles); D. Van Eyck (U.C. St-Jozef, Kortenberg); L. Van Gaal (Dept. of Diabetology, Metabolism and Nutrition, Antwerp); F. Vandendriessche (P.C. Sint-Norbertus, Duffel). 